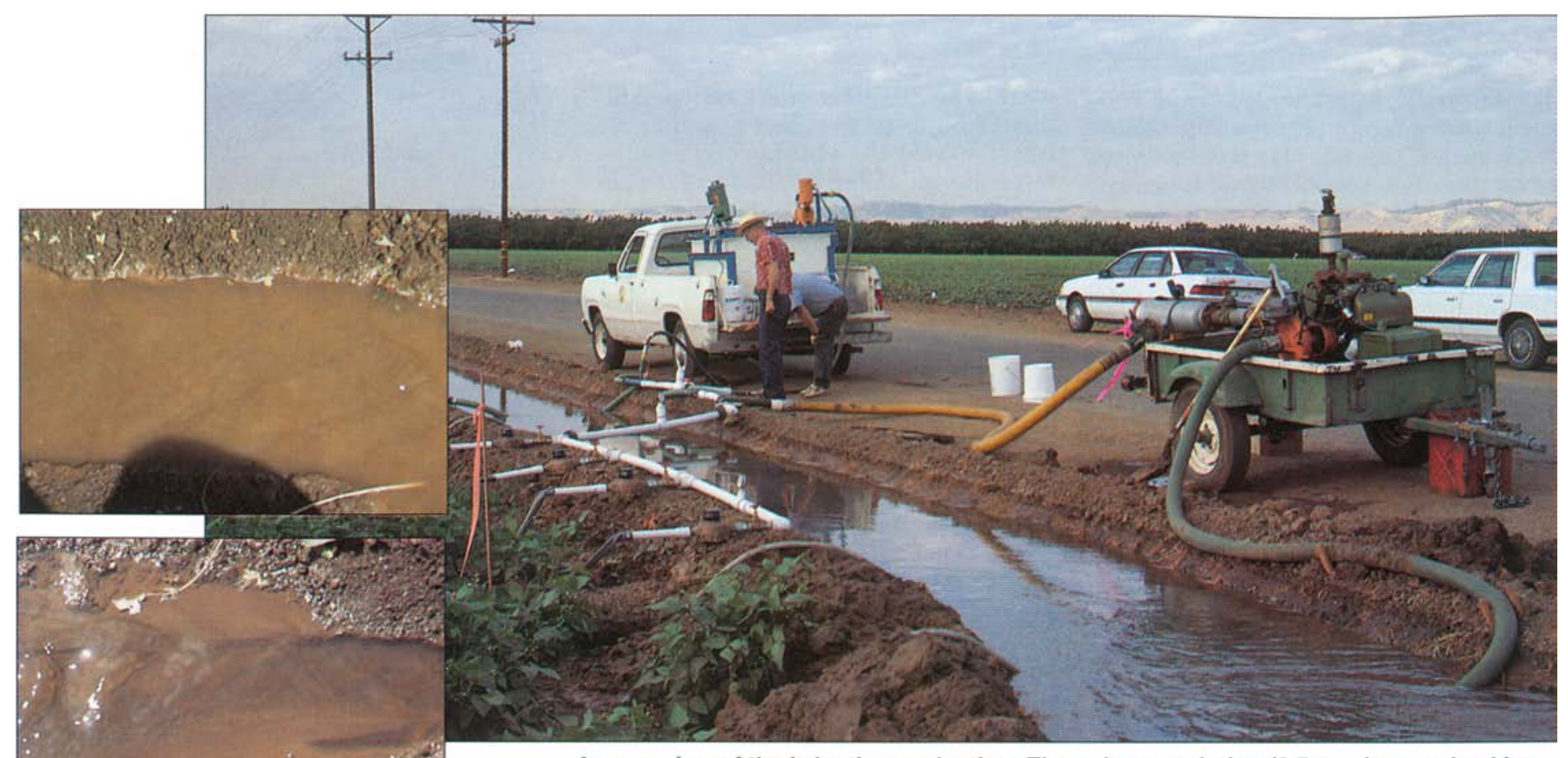

An overview of the irrigation evaluation: The polymer solution $(2.5 \mathrm{ppm})$ was mixed in a tank, injected into a manifold, and metered with a water flow rate of $20 \mathrm{gpm}$ per furrow.

Top, untreated water contained suspended material, which appeared dark brown in color. Below, polymer-treated water flocculated the suspended material causing floccules to settle out and resulting in water clarity.

\section{Polymers check furrow erosion, help river life}

\author{
Hal McCutchan $\square$ Phil Osterli $\square \quad$ John Letey
}

Approximately 1.2 million tons per year of sediment from West Stanislaus

County cropland and orchards are transferred and deposited into the San Joaquin River. Some of the fine-grained soil particles reaching the river carry organochlorine pesticide residues, primarily DDT isomers, a chemical whose use was banned more than 20 years ago.

The physical and chemical characteristics of the sediment reaching the San Joaquin River threaten aquatic and wildlife within this area. These pesticide residues may bioaccumulate in the tissues of organisms ranging from lower feeding invertebrates that consume the contaminated soil particles to organisms higher up the food chain. In addition, the sediment can physically damage the aquatic habitat by decreasing sunlight penetration, disrupting fish behavior and interrupting normal fish spawning and development. As a result, the California State Water Resources Control Board Water Quality Assessment (1990) has designated 100 miles of the San Joaquin River as an impaired water body, including all of Stanislaus County.

West Stanislaus growers have voluntarily adopted Best Management Prac- tices (BMPs) to control erosion and protect the quality of water of the San Joaquin River. Because of poor economic times, growers have hesitated to invest in conservation practices that will not also benefit their immediate income. A more applicable solution for this problem is a conservation practice that would reduce soil erosion with additional benefits, such as increased infiltration rates.

Laboratory and preliminary field studies show that injection of high molecular weight anionic polyacrylamide polymers can potentially reduce erosion and increase infiltration rates as compared to regular water. Based on these observations, a study was initiated to evaluate the effectiveness of injecting polyacrylamide polymers into irrigation water to reduce soil erosion and runoff water from a furrow-irrigated field.

\section{Field evaluation}

In the field evaluation conducted at a Newman, California, spinach field, spinach was planted two rows on 60inch beds. The soil was a Vernalis loam with a slope of 0.46 feet per 100 feet, which is representative of several soil se- 
ries within the area. The fur-

Irrigation water was pumped through a manifold which branched into two sections; one side had the polyacrylamide injected and the other side did not (untreated water). A concentrated polyacrylamide solution was mixed in a tank and injected into the manifold to create a concentration of $2.5 \mathrm{ppm}$. Water was metered into each furrow at 20 gpm to ensure equal application rates and to promote erosive conditions. Two wheel and two nonwheel furrows per treatment were monitored.

Flow near the end of each furrow was measured by collecting water in a container of known volume for a measured stalled with its top flush with the furrow bottom. An apparatus placed in the furrow funnelled the flowing water and sediment into the bucket. Except for when samples were being taken, the water flowed through the funnel into a full bucket, which overflowed into the last segment of the furrow. At sampling time, water was pumped from the bucket, and the water flowing into the bucket through the funnel was collected in a container for sediment analysis.

Samples were analyzed for sediment by two techniques. With one method, samples were mixed and allowed to settle for 5 minutes, after which light transmittance through the water was measured. This measurement determined the concentration of fine particulates (clay and silt) suspended in the water and capable of being transported off the field. Additionally, the total solid material concentration in the sample was measured by drying the sample and weighing the residue. These values, when multiplied by the water flow rate, determine the total sediment load from each furrow.

Advance times (the time required for water to reach the end of the furrow) were taken to evaluate the uniformity of the irrigation based on opportunity time for each treatment. rows were 800 feet long. period of time. A 5-gallon bucket was inControl (wheel) Treated (wheel) Control (nonwheel) Treated (nonwheel)

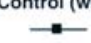

Treated $($ whe $\rightarrow$ - Opportunity time (min)

Fig. 1. Measured outflow rates for polyacrylamide-treated and untreated irrigation water for both types of furrow, wheel and nonwheel, as a function of opportunity time.

\section{Results}

A higher than normal irrigation application rate for this soil type and a slight rainfall (surface sealing) before the study caused a lower advance time than anticipated. Advance times varied from 45 minutes (wheel furrows) to $75 \mathrm{~min}$ utes (nonwheel furrows) (fig. 1), but were not affected by the polyacrylamide treatment. This indicates that the uniformity of the irrigation was not affected by the polyacrylamide. The outflow rates were significantly higher in the wheel furrows than the nonwheel furrows as a result of compaction (fig. 1). In both furrow types, the polyacrylamide-treated water had a $10 \%$ lower outflow rate than the untreated water (significant at the $1 \%$ probability level), indicating a corresponding higher infiltration rate.

Sediment loss, as measured by suspended solid concentrations, total sediment concentration and total sediment load, was significantly lower for the polyacrylamide-treated furrows than the untreated furrows (table 1). The suspended solid concentrations of polyacrylamide-treated furrows were reduced to an average of $0.3 \%$ of the untreated furrows. The polyacrylamide flocculated the suspended soil particles and caused the floccules to settle out. Some floccules were transported along the bottom of the furrow by the flowing water so that the sediment load was not reduced by

TABLE 1. Suspended solids and sediment load collected at the end of the furrow (statistically significant at $\mathbf{5 \%}$ ).

\begin{tabular}{|c|c|c|c|c|c|}
\hline \multirow[t]{2}{*}{ Treatment } & \multirow[t]{2}{*}{$\begin{array}{c}\text { Furrow } \\
\text { type }\end{array}$} & $\begin{array}{c}\text { Sediment } \\
\text { concentration }\end{array}$ & $\begin{array}{c}\text { Suspended } \\
\text { solids }\end{array}$ & \multicolumn{2}{|c|}{$\begin{array}{l}\text { Amount of } \\
\text { sediment } \\
\text { after } 5 \mathrm{~min} \\
\text { settling }\end{array}$} \\
\hline & & $n$ & A & ............. & ................... \\
\hline Control & $\begin{array}{l}\text { Wheel } \\
\text { Nonwheel }\end{array}$ & $\begin{array}{r}1,335 a \\
978 b\end{array}$ & $\begin{array}{l}700 \mathrm{a} \\
627 \mathrm{~b}\end{array}$ & $\begin{array}{l}.36 \mathrm{a} \\
.18 \mathrm{~b}\end{array}$ & $\begin{array}{l}0.19 a \\
0.11 b\end{array}$ \\
\hline \multirow[t]{2}{*}{ Polyacrylamide } & Wheel & $483 c$ & $2 c$ & $.12 \mathrm{c}$ & $<0.01 c$ \\
\hline & Nonwheel & $435 c$ & $1 \mathrm{c}$ & $.06 \mathrm{c}$ & $<0.01 c$ \\
\hline
\end{tabular}

the polymer treatment as much as the suspended solids. The total sediment concentration of the polyacrylamidetreated furrows were 36 and $44 \%$ of the untreated furrows for the wheel and nonwheel furrows respectively. Because the polymer treatment reduced the amount of water leaving the field, the total amount of sediment leaving the field would also be reduced.

\section{Conclusion}

Injecting polyacrylamide into irrigation water is a promising soil conservation practice as indicated by a reduction of sediment and runoff leaving the field. Flow velocity and roughness on the bottom of the furrow determined the extent that the floccules would be transported along the furrow.

Without proper irrigation water management, soil erosion will continue to reduce soil productivity and severely damage the river's aquatic habitat. At current prices, we estimate that a polyacrylamide application would range from $\$ 15$ to $\$ 20$ per acre-feet of water. Additional BMPs, such as a sediment basin, would still need to be incorporated into the farming operation, but at a reduced size and a lower cost for installation and maintenance.

Based on results to date, it appears that the polyacrylamide may need to be applied in each irrigation. Further evaluations will be needed to determine the most effective concentration, the number of applications per season and the effectiveness on various soil types.

As shown by this field evaluation, there are clear benefits in adding polyacrylamides to irrigation water. Besides sediment reduction, water quality and infiltration are improved at a relatively low cost. Based on these studies, growers should have additional methods to solve their water quality problem in West Stanislaus County and avoid a possibility that their access to the San Joaquin River could be curtailed and state-regulated practices mandated.

H. T. McCutchan is a Postgraduate Researcher, UC Cooperative Extension, Stanislaus County; P. P. Osterli is County Director and Farm Advisor, Stanislaus County; and J. Letey is Professor of Soil Physics, Department of Soil and Environmental Sciences, UC Riverside.

The authors would like to acknowledge Gary Mall of Orestimba Ranches for his assistance; Allied Colloids, Inc. for providing the polymer and equipment; and laboratory and field support from Laboratory Technician Neil Jacklin and Field Assistant Ray Hill, both of UC Cooperative Extension. 